\title{
Report on Laboratory Tests of Drying and Re-Wetting of Intact Rocks from the Drift Scale and Single Heater Tests
}

\author{
J.J. Roberts \\ E. Carlberg \\ R. Pletcher \\ W. Lin
}

January 1998

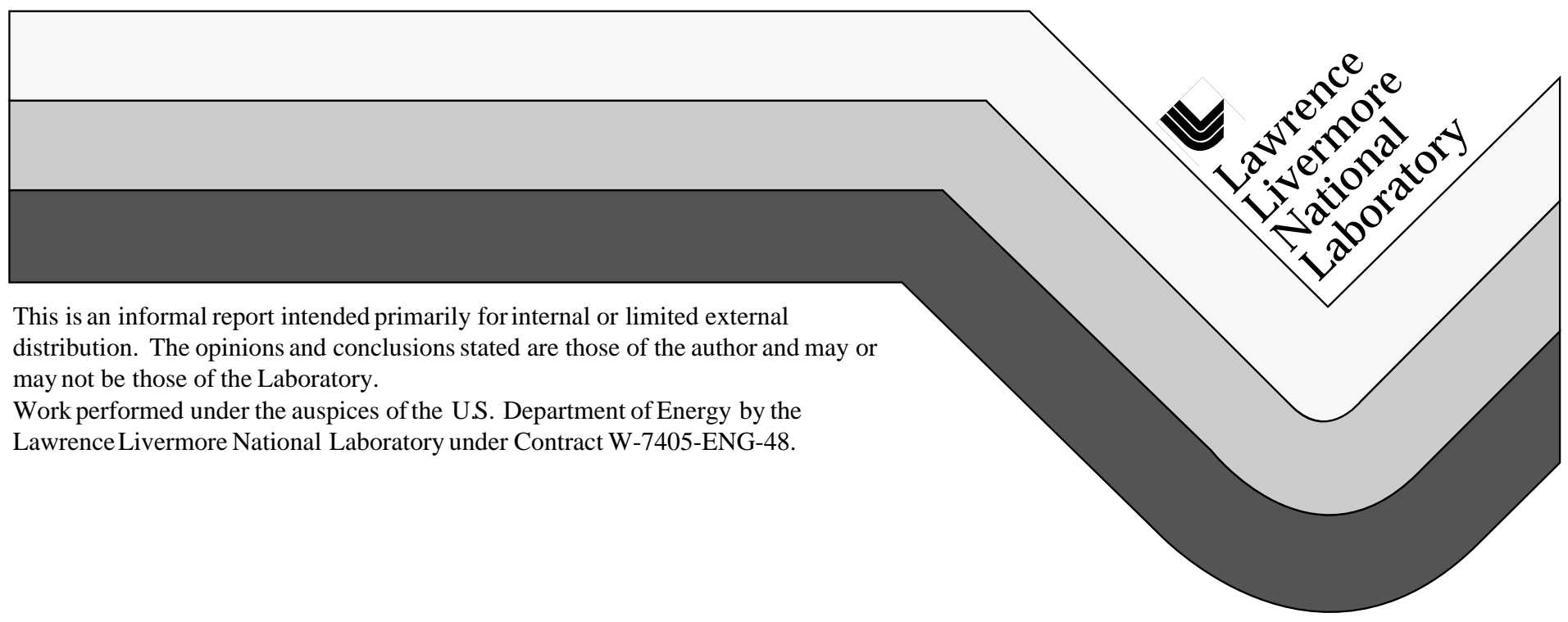




\section{DISCLAIMER}

This document was prepared as an account of work sponsored by an agency of the United States Government. Neither the United States Government nor the University of California nor any of their employees, makes any warranty, express or implied, or assumes any legal liability or responsibility for the accuracy, completeness, or usefulness of any information, apparatus, product, or process disclosed, or represents that its use would not infringe privately owned rights. Reference herein to any specific commercial product, process, or service by trade name, trademark, manufacturer, or otherwise, does not necessarily constitute or imply its endorsement, recommendation, or favoring by the United States Government or the University of California. The views and opinions of authors expressed herein do not necessarily state or reflect those of the United States Government or the University of California, and shall not be used for advertising or product endorsement purposes.

This report has been reproduced directly from the best available copy.

Available to DOE and DOE contractors from the Office of Scientific and Technical Information P.O. Box 62, Oak Ridge, TN 37831

Prices available from (423) 576-8401

Available to the public from the National Technical Information Service

U.S. Department of Commerce 5285 Port Royal Rd. Springfield, VA 22161 


\title{
Report on Laboratory Tests of Drying and Re-wetting of Intact Rocks From the Drift Scale and Single Heater Tests
}

\author{
Jeffery J. Roberts, Eric Carlberg, Ron Pletcher, and Wunan Lin \\ Lawrence Livermore National Laboratory \\ January 15, 1998 \\ Introduction
}

The primary focus of this report is the measurement of moisture retention curves of tuff as a function of temperature for both drying and re-wetting conditions. The report contains descriptions of experimental designs and procedures, data, observations, preliminary analyses, and future work.

Knowledge of unsaturated transport properties is critical for understanding the movement of water through the unsaturated zone. Evaluation of the performance of a potential nuclear waste repository also depends on these properties. Moisture retention data are important input for numerical models of moisture movement in unsaturated porous media. Also important is the effect of sample history on the moisture retention curves, and whether or not there is significant hysteresis between wetting and drying measurements. This report addresses initial observations regarding this aspect of the research. Previous measurements of the matric potential of tuff are reported by Roberts and Lin (1995), and in the Near Field Environment Report (Wilder, 1996).

\section{Experimental Procedure}

Sample Description and Preparation. Samples from the Drift Scale Test (DST) and Single Heater Test (SHT) from the Exploratory Studies Facility (ESF), Nevada Test Site (NTS) were prepared from cores taken from the chemistry boreholes. Tables 1 and 2 list the ID numbers, borehole, depth, wet and dry densities, and porosity. Thirteen DST samples, and eleven SHT samples were prepared. The samples were subcored to a diameter of between 4.4 and $6.1 \mathrm{~cm}$ and cut into disks approximately 2.5 to $3.0 \mathrm{~mm}$ thick. Samples with obvious large cavities and inhomogeneous inclusions were avoided. The porosity of each sample was determined by subtracting the dry 
density from the saturated density and dividing by the water density. The average porosity for the DST samples is $10.0 \pm 1.7 \%$ and for the SHT samples is $11.1 \pm 1.1 \%$.

Calculation of matric potential. The matric potential is the pressure potential that arises from the interaction of water with a solid matrix (Marshall and Holmes, 1992). In tuff we assume that the suction potential is equal to the matric potential. Matric potential is defined by Kelvin's Law as

$$
\psi=\beta \mathrm{R} \mathrm{T} \ln \left(\mathrm{e} / \mathrm{e}_{0}\right) / \mathrm{M}
$$

where $\psi$ is the matric potential in $\mathrm{MPa}, \beta$ is the density of water at the temperature of interest in $\mathrm{g} / \mathrm{cm}^{3}, \mathrm{R}$ is the universal gas constant $(8.314 \mathrm{~J} / \mathrm{Kmol}), \mathrm{T}$ is temperature in $\mathrm{K}$, e/ $\mathrm{e}_{0}$ is the relative humidity RH, and $\mathrm{M}$ is the molecular weight of water $(18.015 \mathrm{~g} / \mathrm{mole})$.

To determine the moisture retention curve, samples were placed in the humidity chamber at a specific temperature and $\sim 20 \%$ the relative humidity $(\mathrm{RH})$. Measurements began on dry samples. When the weights reached a constant value for several days (samples weighed daily) it was assumed that equilibrium was established. When a stable weight was achieved, the RH was increased and the process repeated at the same temperature. The maximum saturations achieved at the highest RH ( $98 \%$ ) were between 30 and $40 \%$ (vide infra). A balance with a sensitivity of $0.01 \mathrm{mg}$ calibrated to a traceable standard was used to weigh the samples. Saturation is calculated by comparing weights with dry weights and taking into account porosity. The process was then repeated for the drying portion of the measurement. This cycle of measurement was then repeated at different temperatures.

The following procedure was used to perform the measurements. First the samples were machined, and the dimensions measured. Next, the samples were placed in a vacuum oven at $35^{\circ} \mathrm{C}$ to reach a completely dry state. The samples were then placed in the relative humidity chamber at $25.1^{\circ} \mathrm{C}$ and $20 \% \mathrm{RH}$. When a stable weight (corresponding to a saturation) was achieved, the RH was increased to $50 \%$. This was repeated as the RH was increased to 80 , and then $95 \%$. After this, the RH was decreased according to the following steps: 80,50 , and $20 \%$ RH. This procedure was then repeated for all samples at the next temperature, $49.6^{\circ} \mathrm{C}$. The SHT 
samples at $25.1^{\circ} \mathrm{C}$ had additional measurements performed at 35 and $65 \% \mathrm{RH}$, during both wetting and drying.

\section{Measurement Uncertainty}

The uncertainties involved in the determination of the moisture retention curves include the measurements of weights, relative humidity and sample size. The sample dimensions are used to determine sample wet and dry densities. It is estimated that the thickness of the sample can be determined to $\pm 0.01 \mathrm{~mm}$ and diameter to $\pm 0.03 \mathrm{~mm}$. For the samples used here, this results in an error in sample volume of $\sim \pm 0.4 \%$. The uncertainty in dry weight is estimated to be $\sim 0.00002 \mathrm{~g}$ and for wet weight $\sim 0.0001 \mathrm{~g}$. The error in the wet weight is higher than that of the dry condition because of the difficulty in achieving and maintaining saturation levels of $100 \%$ at elevated temperature. These uncertainties result in errors in dry and wet densities of $\sim 3 \%$. When propagated through to porosity, the error is $\sim 1.0 \%$ porosity, or $\sim 7-11 \%$ of the measurement (Bevington and Robinson, 1992).

When repetitive measurements are made on samples over a period of several days, such as the determination of weights at a specified relative humidity, for example, the uncertainty in the measurement is often less than the statistical uncertainty in the mean of the measured parameter. In such cases the error is taken as one standard deviation of the mean of the repeated measurements. The errors in saturation determined at specific temperature and $\mathrm{RH}$ vary from $\sim 0.07$ to $0.4 \%$ Sw. Thus, the relative uncertainty is between $\sim 1$ and $10 \%$, with a $1-2 \%$ error most common.

The uncertainty in the relative humidity is approximately $\pm 2 \% \mathrm{RH}$. When propagated through equation 1 to matric potential, the absolute uncertainties are fairly low, but the relative uncertainties are high at the matric potentials closest to zero.

The temperatures reported are the mean temperatures recorded during the time periods of the measurements. The highest statistical uncertainty (one standard deviation) is about $\pm 0.6^{\circ} \mathrm{C}$, but is generally less than $\pm 0.3^{\circ} \mathrm{C}$. 


\section{Results and Discussion}

DST Samples. Moisture retention curves at $25.1^{\circ} \mathrm{C}$ and $49.6^{\circ} \mathrm{C}$ are shown in Figures 1 and 2. Only the 'average' properties are shown for clarity. The averages are the mean saturation for all samples calculated at a specific RH (matric potential). The error bars for saturation are the standard deviation of five measurements taken when a stable weight (saturation) was achieved. There is very little hysteresis observed between the wetting and drying curves. Previous measurements on similar samples showed significant hysteresis under certain conditions (Wilder, 1996). There is also very little difference between the 25.1 and $49.6^{\circ} \mathrm{C}$ curves. For comparison,

samples from USW-G4 (NTS borehole) showed a significant temperature dependence of moisture retention on temperature (Roberts and Lin, 1995).

SHT Samples. The moisture retention curves for the SHT samples are shown in Figures 3 $\left(25.1^{\circ} \mathrm{C}\right)$ and Figure $4\left(49.6 \mathrm{C}^{\circ}\right)$. Again we report average saturations with errors as described for the DST samples. Similar to the case for the DST samples there is neither hysteresis evident nor a notable temperature dependence.

The maximum saturation increases with increasing temperature for both DST and SHT samples. At $25.1^{\circ} \mathrm{C}$ the maximum saturation achieved is $\sim 30 \%$ for the DST samples and $\sim 36 \%$ for the SHT samples. At $49.6^{\circ} \mathrm{C}$ this increases to $\sim 40 \%$ for the DST samples and $\sim 39 \%$ for the SHT samples. These saturations are higher than those reported for USW-G4 and LBT samples which were $\sim 30 \%$ saturation at the highest RH. 


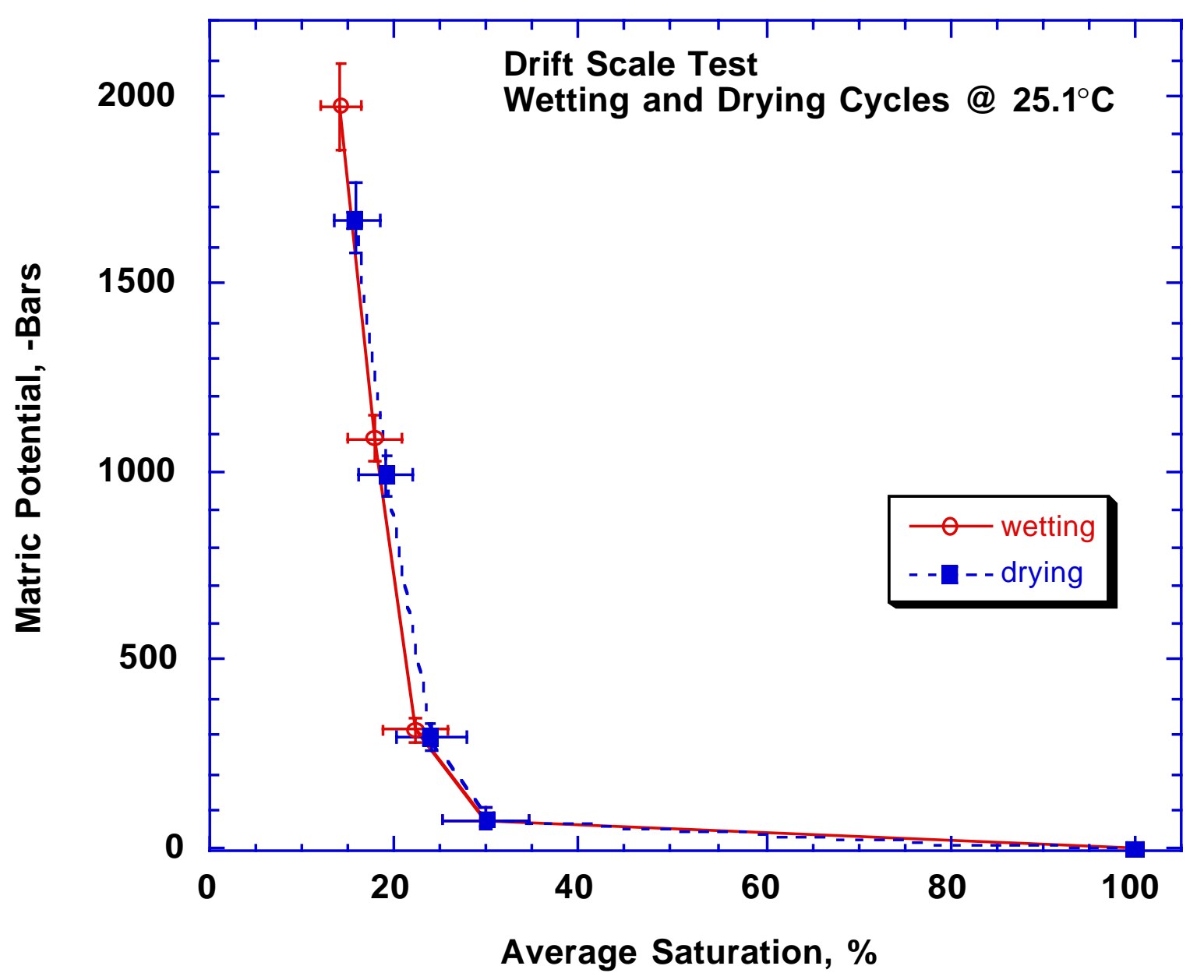

Figure 1. Matric potential versus average saturation for 13 DST samples at $25.1^{\circ} \mathrm{C}$. Solid line indicates the wetting curve, and dashed line indicates drying curve. Point at $100 \%$ saturation is inferred. 


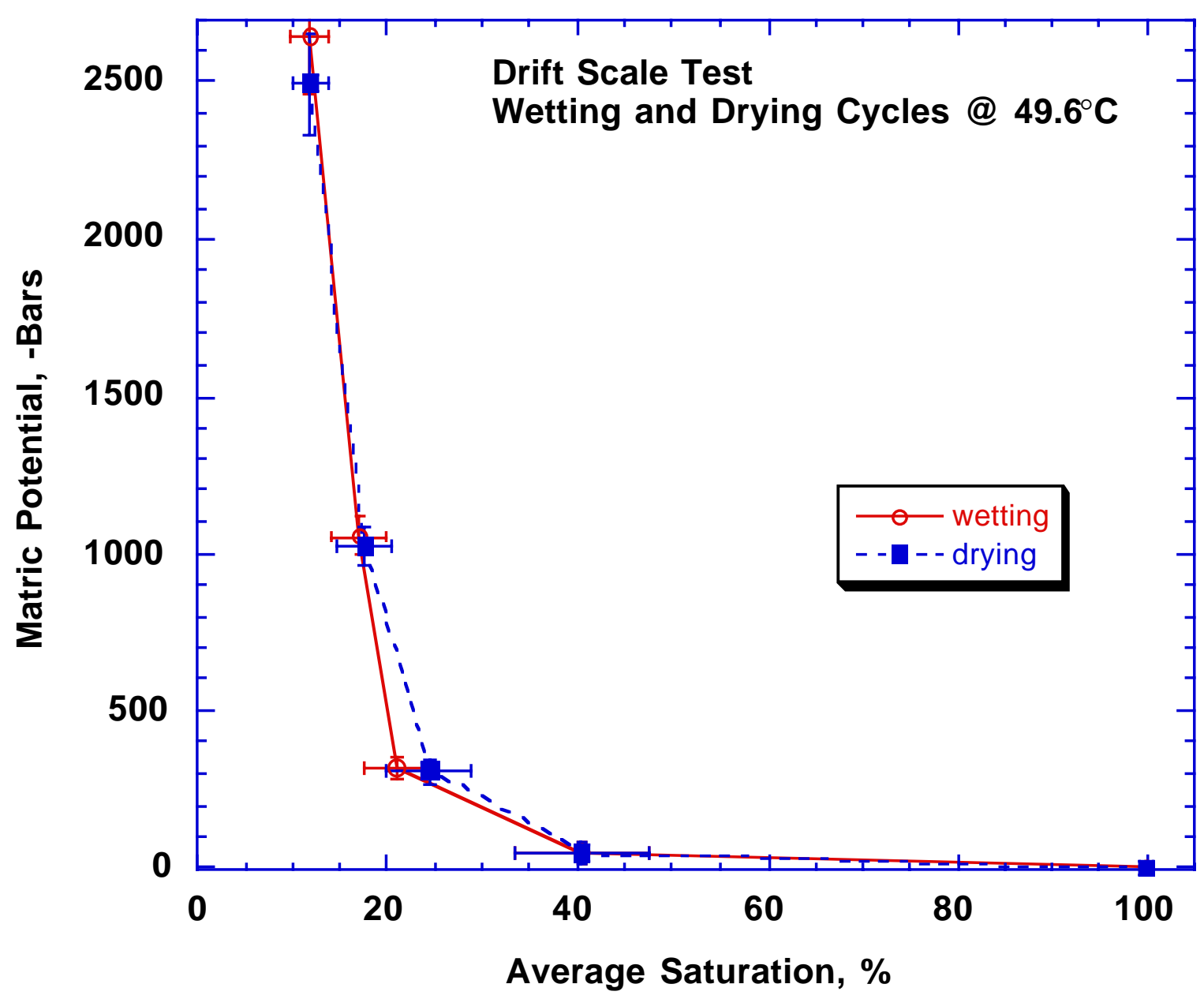

Figure 2. Matric potential versus average saturation for $13 \mathrm{DST}$ samples at $49.6^{\circ} \mathrm{C}$. Solid line indicates the wetting curve, and dashed line indicates drying curve. Point at $100 \%$ saturation is inferred. 


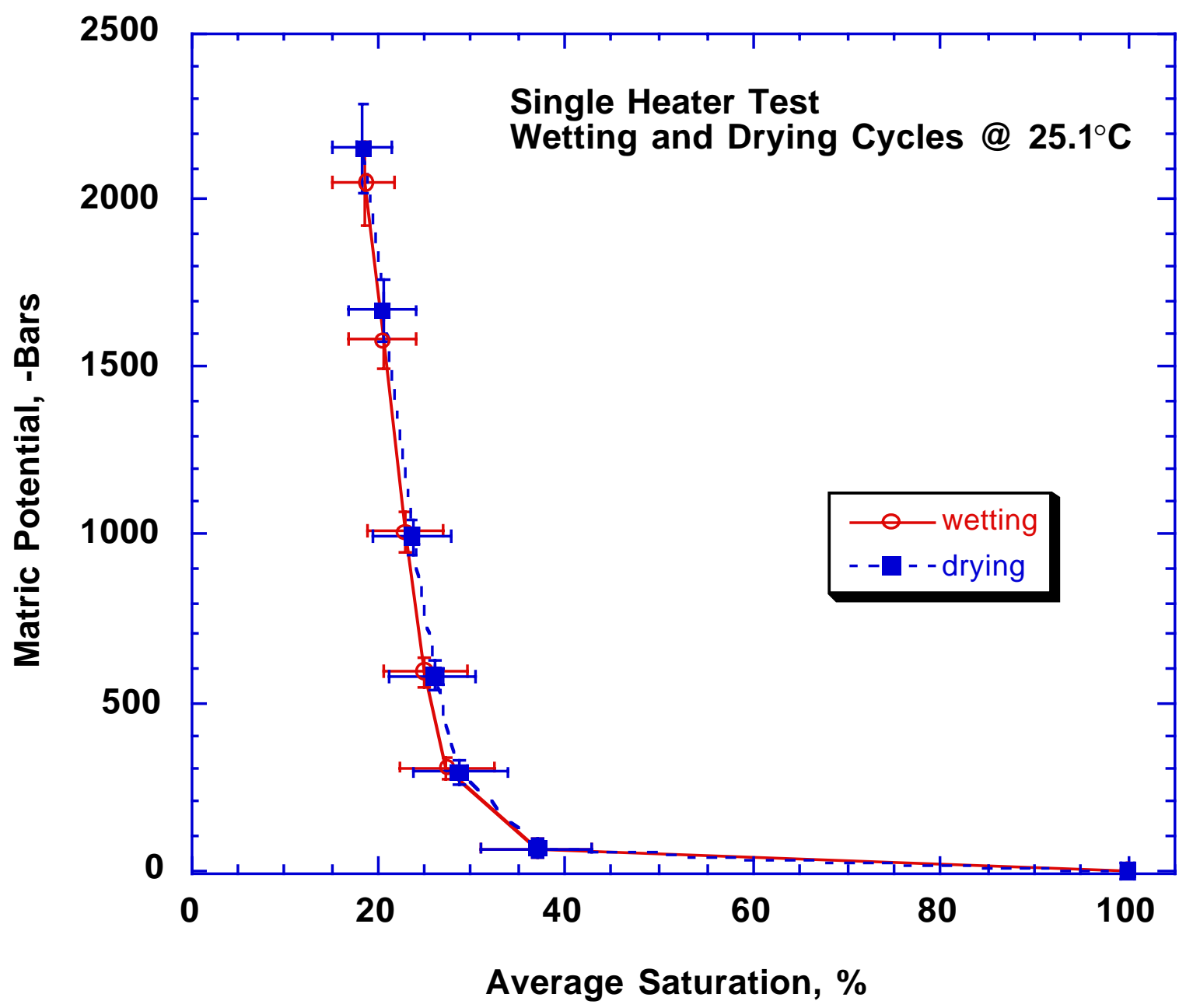

Figure 3. Matric potential versus average saturation for $11 \mathrm{SHT}$ samples at $25.1^{\circ} \mathrm{C}$. Solid line indicates the wetting curve, and dashed line indicates drying curve. Point at $100 \%$ saturation is inferred. 


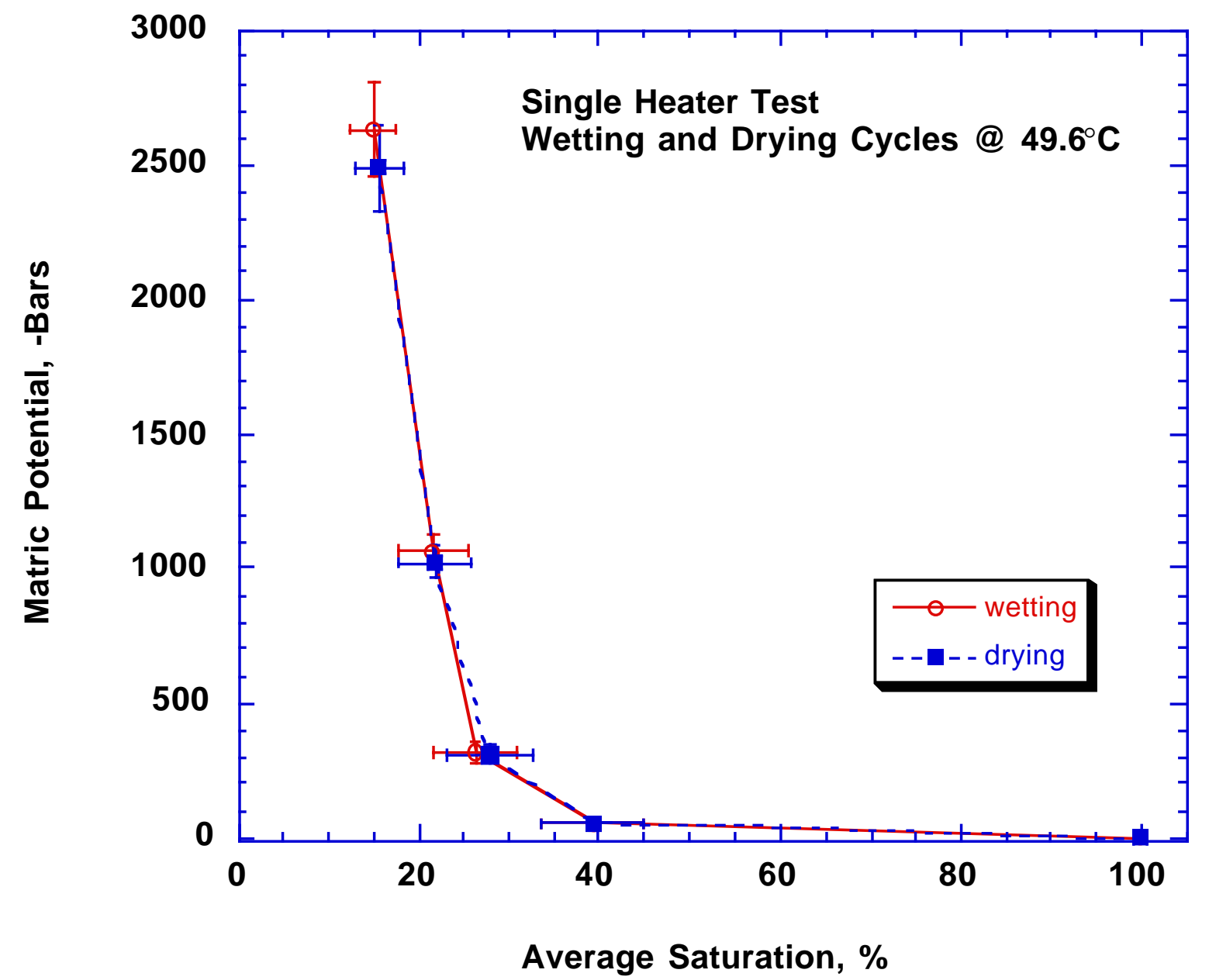

Figure 4. Matric potential versus average saturation for $11 \mathrm{SHT}$ samples at $49.6^{\circ} \mathrm{C}$. Solid line indicates the wetting curve, and dashed line indicates drying curve. Point at $100 \%$ saturation is inferred.

\section{Future work}

The measurements on both DST and SHT samples will continue at higher temperatures. The next temperature of measurement will be 90 to $95^{\circ} \mathrm{C}$. Measurements at a lower temperature will be repeated in order to assess the effect of higher temperature excursions on the repeatability of the previous (low temperature) measurements. A new set of measurements of liquid sorptivity is currently planned and samples are being prepared. These measurements will consist of one dimensional sorptivity measurements into cylinders of intact tuff as functions of temperature. The one dimensional sorptivity experiment will take place in an oven for temperatures below $100^{\circ} \mathrm{C}$ and in a high pressurized humidity chamber for temperatures greater than $100^{\circ} \mathrm{C}$. 
Acknowledgments. Dave Ruddle provided technical support. This work was supported by the Yucca Mountain Site Characterization Project. Work performed under the auspices of the US. Department of Energy by Lawrence Livermore National Laboratory under contract W-7405ENG-48.

\section{References}

Bevington, P. R., and D. K. Robinson, Data reduction and error analysis for the physical sciences, 2nd ed., McGraw-Hill, San Francisco, 328p, 1992.

Marshall, T. J., and J. W. Holmes, Soil physics, 2nd ed., Cambridge University Press, Cambridge, 374p., 1992.

Roberts, J. J., and W. Lin, Hydrological property measurements of Topopah Spring Tuff, Rep. UCRL-ID-119033, Lawrence Livermore Natl. Lab., Calif., 1995. 
Table 1. Drift Scale Test samples prepared for moisture retention experiments.

\begin{tabular}{llllll}
\hline \hline Sample ID & Borehole & Depth, $\mathrm{m}$ & $\begin{array}{c}\text { wet density, } \\
\mathrm{g} / \mathrm{cm}^{3}\end{array}$ & $\begin{array}{c}\text { dry density, } \\
\mathrm{g} / \mathrm{cm}^{3}\end{array}$ & porosity \\
\hline \hline $01002163-1$ & CHE-1 & $92.3-93.2$ & 2.371 & 2.286 & 0.0853 \\
$01002176-1$ & CHE-2 & $128.9-129.6$ & 2.322 & 2.211 & 0.111 \\
$01002179-1$ & CHE-5 & $39.4-40.1$ & 2.386 & 2.303 & 0.0831 \\
$01002189-1$ & CHE-6 & $43.4-44.1$ & 2.307 & 2.216 & 0.0914 \\
$01002190-1$ & CHE-6 & $63.9-64.6$ & 2.375 & 2.292 & 0.0835 \\
$01002194-1$ & CHE-6 & $99.7-100.4$ & 2.330 & 2.224 & 0.106 \\
$01002199-2$ & CHE-7 & $51.9-52.6$ & 2.301 & 2.174 & 0.127 \\
$01002200-1$ & CHE-7 & $80.0-80.7$ & 2.363 & 2.273 & 0.0895 \\
$01002206-2$ & CHE-10 & $15.7-16.3$ & 2.329 & 2.227 & 0.102 \\
$01002207-2$ & CHE-10 & $27.3-28.0$ & 2.400 & 2.311 & 0.0891 \\
$01002209-2$ & CHE-10 & $75.6-76.3$ & 2.379 & 2.254 & 0.125 \\
$01002212-1$ & CHE-10 & $91.6-92.3$ & 2.368 & 2.243 & 0.124 \\
$01002215-1$ & CHE-10 & $124.0-124.7$ & 2.361 & 2.282 & 0.0796 \\
\hline mean* & & 13 samples & $2.35 \pm 0.03$ & $2.25 \pm 0.04$ & $0.100 \pm 0.017$ \\
\hline
\end{tabular}

*Statistical mean for 13 samples. Errors represent one standard deviation for all samples collectively.

Table 2. Single Heater Test samples prepared for moisture retention experiments.

\begin{tabular}{llllll}
\hline \hline Sample ID & Borehole & Depth, $\mathrm{m}$ & $\begin{array}{c}\text { wet density, } \\
\mathrm{g} / \mathrm{cm}^{3}\end{array}$ & $\begin{array}{c}\text { dry density, } \\
\mathrm{g} / \mathrm{cm}^{3}\end{array}$ & porosity \\
\hline \hline 0047525.2 & CHE-1 & 2.20 & 2.348 & 2.247 & 0.102 \\
$0047525.2 \mathrm{~A}$ & CHE-1 & 2.30 & 2.350 & 2.249 & 0.102 \\
0047526.2 & CHE-1 & 4.60 & 2.349 & 2.240 & 0.109 \\
0047527.2 & CHE-1 & 8.20 & 2.345 & 2.246 & 0.0998 \\
0047528.2 & CHE-1 & 12.5 & 2.331 & 2.224 & 0.107 \\
0047529.2 & CHE-1 & 14.0 & 2.344 & 2.235 & 0.109 \\
$0047530.2 \mathrm{~A}$ & CHE-2 & 14.8 & 2.294 & 2.167 & 0.127 \\
0047531.2 & CHE-2 & 5.00 & 2.332 & 2.222 & 0.111 \\
0047533.2 & CHE-2 & 12.7 & 2.290 & 2.156 & 0.135 \\
0047534.2 & CHE-2 & 15.2 & 2.331 & 2.229 & 0.103 \\
0047535.2 & CHE-2 & 17.6 & 2.314 & 2.195 & 0.119 \\
\hline mean* & & 11 samples & $2.33 \pm 0.02$ & $2.22 \pm 0.03$ & $0.111 \pm 0.011$ \\
\hline
\end{tabular}

*Statistical mean for 11 samples. Errors represent one standard deviation for all samples collectively. 


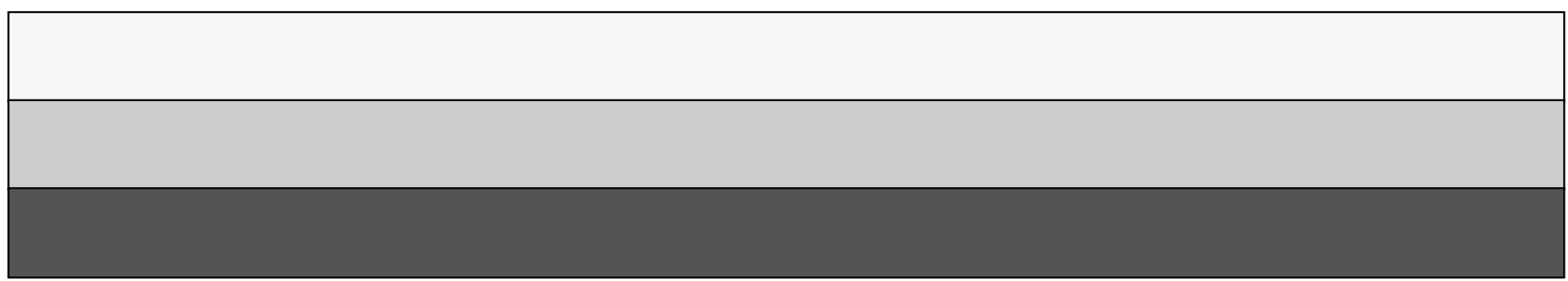

